masonry dam. It has since been carried out by $\mathrm{Mr}$. Deacon solely, as engineer-in-chief.

It has been constructed at Vyrnwy under conditions very similar to those of the Furens reservoir, in France, and of the Karakvasla dam, near Poonah, in India, constructed by General Fife, R. E. The rock bar cros ing the lower end of the valley was laid bare by an ex cavation 1,100 feet long, 120 feet wide, and from 40 to 60 feet below the surface, removing the alluvial deposit sloping rocks were benched or stepped to make a thoroughly solid foundation for the masonry. The thoroughly solid foundation for the masonry. The
river was diverted, and the building was then begun. The stone of which the dam is built was taken from a quarry about a mile distant, to the nörth. This stone, like that of the foundation, belongs to the rock strata of the Lower Silurian system. It is a hard, durable, dark gray stone, weighing 2.06 tons per cubic yard, and having a specific gravity of about $2 \cdot 721$. Stones weigh ing 10 tons were the largest size allowed to be built into the work, but the average weights were: Stones under 2 tons, 45.99 per cent; stones from 2 to 4 tons, $20 \cdot 86$ per
cent ; stones 4 tons and upward, 33.15 per cent. The cent; stones 4 tons and upward, $33 \cdot 15$ per cent. The
lower beds of these stones, if not perfectly flat, were roughly dressed to a plane surface, and any overhang ing pieces or undue projections were cut off. They were then washed by

of a 140 foot head.

The stone was too hard for pick work; hammer and chisel, or hammer and set, were, therefore, almost $\epsilon \mathrm{X}$ clusively used. When brought to the dam by locomotives and wagons running on a 3 foot gauge railway, they were lifted into position by steam cranes and deposited on a bed of Portland cement mortar. The interstices between the large stones, when important enough, were then built up with smaller ones, around which cement concrete was rammed. On the finished which cement concrete was rammed. On the finished
surfaces so obtained fine Portland cement mortar was again spread, in which other similar stones were set and beaten down with heavy malls. No grouting of any kind was allowed, the necessary intimate mixture and density being obtained by ramming. The cement mortar was at first made with cleanly washed sharp river cement. This was afterward abandoned for a mortar made of one part of pulverized rock mixed with two made of one part of pulverized rock mixed with two
parts of clean river sand, and of this two parts were parts of clean river sand, and of this two parts were
mixed with one part of cement. From this pulverized stone, sand, and cement a stronger mortar was obtained than from sand and cement only; the mixture also was quite free from "shortness." As the wall was raised

After Mr. Hawksley retired from the joint engineership, and in consequence of certain statements that he
had made, the Liverpool Corporation instituted a scienhad made, the Liverpool Corporation instituted a scien-
tific inquiry into the stability of the structure and the quality of the materials employed. One of those who then examined it was General Sir Andrew Clark, R.E., then Inspector-General of Fortifications. In the course of the inquiry a vertical shaft was sunk and a heading driven into the heart of the dam. Eleven large blocks of the concrete filling were removed. When tested. by Professor Unwin, F.R.S., and Mr. Kirkaldy, they were found to bear, before erushing, an average load of 300 tons per square foot. The masonry was found to be of
the highest character, both as to the concrete filling and mortar bedding. Of the cement, the average tensile strength was $61 / 2 \mathrm{cwt}$. per square inch. Sir Audrew Clark said of this masonry that "nothing short of an earthquake could possibly disturb it."

earthquake could possibly disturb it."

The total length of chis huge masonry dam across the
mouth of the valley is 1,172 feet; its greatest thickness mouth of the valley is 1,172 feet; its greatest thickness
at the base is 120 feet; its height, from the lowest part at the base is 120 feet; its height, from the lowest part of the foundation to the parapet of the carriage road on the top, is 161 feet, and from the bed of the river or
lake, 101 feet; the height from the bed of the lake to the sill for the overflow of water is 84 feet, which will thus be the maximum depth of the lake. The dam has a " batter," or slope, above the level of the ground, to the degree of 1 in 1.5 on the lake side and 1 in $7 \cdot 27$ on the outer side. The total quantity of masonry in this dam is 260,000 cubic yards, weighing 509,700 tons. The illustration is a view of the outer side of the dam, from a sketch taken by our special artist, Mr. W. Simpson, in the autumn of last year, before the rising of the water in the lake, and while the building of arches on the summit, of which there are thirty-three, elliptical
in form, with spans of 25 feet, was still in progress. in form, with spans of 25 feet, was still in progress.
These arches now suppcrt a viaduct for the carriage These arches now support a viaduct for the carriage
road, 19 feet wide, and two side pathways; also two finely proportioned towers, containing shafts and ap paratus controlling the valves in the two tunnels discharge of water from the lake to the river Vyrnwy. From the valley below the lake the outer side of the whole structure appears complete, and these two tunnels are seen with the streams of water flowing from
them down the valley. Each aperture is 15 feet in in diameter; but at present both have been filled the port end of the rudder yoke. The steering whee up with brickwork and cement, to allow the lake is attached to a horizontal spindle, the forward end of above to fill with water, leaving only, in the center $\mid$ which bears a small geared wheel. The spindle can be est recorded speed for a three hour trial for a boat of of each tunnel, an iron pipe governed by two pushed slightly forward or pulled aft in its bearings, and her displacement carrying a load (in eoal, water, crew,

can be locked in either position by a small drop pawl. the teeth of the rack, and, when aft, it engages with multiplying gearing connected with the rack. The latter position, giving more power to the wheel, is habitually used in steering by hand power alone. The spindle has a slight lateral play in its bearings. Its after end is connected by a system of light rods and bent levers with the valve of the steering cylinder, so that
whenever the wheel is turned to starboard or to port, the spindle works to one side or the other, and the valve is moved to open the forward or after steam ports of the cylinder. When rotation of the wheel ceases, the spindle resumes its middle position and the valve is centered. Thus, the steam steering gear is always at-
tached, and it is only necessary to turn on steam to the tached, and it is only necessary to turn
cylinder when it is desired to use it.

The boiler is a Herreshoff patent square tubular, or coil, boiler, 66 inches square outside and 7 feet high, with ten flats of pipes, 58 inches square, the pipes decreasing in diameter from $31 / 2$ inches in the first two flats to $1 \frac{1}{2}$ inches in the last two, giving a heating sur-
face of 552 square feet on the inside of the pipes. Weight of boiler, 10,343 pounds. The separator, of wrought iron, is 6 feet high and 18 inches in diameter. The Stiletto, illustrated in this issue, built at Bristol, Under the cabin is a water tank with a capacity for 200 R. I., by the Herreshoff Manufacturing Company, was gallons, joined by piping with one under the boiler and launched February 25, 1885, and was purchased by the firing flat, holding 300 gallons. A steam in jector and a Blake steam pump connect these tanks with the Blake
boiler.

She is a high pressure, singie screw, wooden vessel of engine room and fire room being of extra strength The second compartment, 24 feet long, contains the ide. Oil lamps are used at night. heads. The piston, with its rods, forms, virtually, a mounted forward, on deck, and ca $31: 8$ tons displacement to the load water line, 90 feet long between perpendiculars, 94 feet long over all, of 11 and of 2 feet 10 inches draught.

In her construction lightness is combined with trength. The framing is of white oak, the keel being boards are side-bolted to the keel; and the frames, spaced 15 inches, and extending from the gunwale to the keel, are securely bolted to the latter and to the which and to the frames they are bolted; the frames re strung together by a thick strake 2 feet above the water line, a top strake, and a gutter strake lapping
over the top strake and the ends of the deck beams he stem and the stern post are of white oak siding. Tent working and twisting, those in the wake of the rossing in opposite directions. These straps are outside of oak, are fastened to the frames by malleable iron knees, lightened by holes and bolted through. The side planking is in two thicknesses, butts and seams
breaking joints. The inner planks are of white pine, the outer of yellow pine from garboards to the thick rake and of white pine above them. The deck plank-
ing is in two thicknesses of white pine. The seams are ot calked, but a layer
he two thicknesses.

The boat is divided by five bulkheads into six wateright compartments. The collision bulkhead is $71 / 2$ tows in the compartment formed by this bulkhead. the third, $18 \frac{1}{2}$ feet in length, is the boiler room; the ourth, 11 feet long, is the engine room; the fifth, 24 eet from bulkhead to bulkhead, contains the galley ong, is a store room.

The second compartment is entered through the conang tower, the third, fourth, and fifth by hatchways, cover is fitted with a spring catch, and this, as well as and other covers, can be opened from

The interior receives light in the daytime through

The conning tower, about 4 feet in diameter, rises $23 / 4$ eet above the deck, and has glazed slits for an all has conveniently at hand the steering handles, the aparatus for signaling to the engine room, and the histle lever.

The boat can be steered by hand or by steam. In cylinder, with a stroke of 24 inches. To its pistos are
che connected two piston rods-a forward and an after one - traveling through stuffing boxes in the cylinder part of the starboard wheel rope, the after rod being that torpedoes may be discharged in any direction connected by steel wire rope to the rudder yoke and comprehended within an arc considerably in excess of

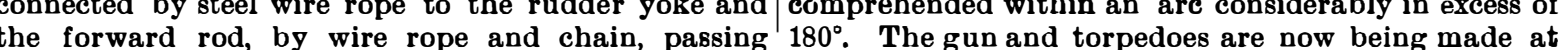
$180^{\circ}$. The gun and torpedoes are now being made

The enviable distinction belongs to the Stiletto of having made, first, the highest recorded speed for a boat $(a)$ of her length and $(b)$ of her displacement, over

In the boiler room is a steam ejector for
compartments from water in case of leaks.

Abaft the boiler, and in the same compartment, is

rate surface. 21 square feet. The ashes pass out by a d, the space within the jacket forming an efficient entilator when working with open fire room.

Forced draught is given by a centrifugal fan, $31 / 2$ feet
diameter, driven by an independent engine, $31 / 2$ The engines are vertical direct-acting Herreshoff compound condensing engines, with two cylinders act-
ng on cranks at $90^{\circ}$. Diameter of high pressure cylinThe cylinders are supported by eight upright steel rods,
Thes 4 inches in diameter, rising from the bed plate and re-
enforced by stay rods and braces. The bed is of steel plate, cut for the cranks, and with lighting holes in the this bed and the engine is not otherwise secured to the engin reducing the liability to derangement of Around the top and bottom of the cylinders are
lines of ports controlled by ring valves, the valves at top and bottom being connected by stay rods, and the ed. Each pair of valves is worked by four stems secured to the lower ring at equal distances apart and Y-shaped rock hausted from the ends. In this engine the cslinder is
hald all times surrounded by live steam, and is, therefore, ficient working. The valves are balanced. The clearcylinder at once, there is but little wire drawing. The condenser, of copper, is 5 feet long and 2 feet in
diameter, over all, and contains 684 tubes. Water is driven through it by an independent centrifugal pump, Sing 70 revolutions at full speed.

Six pumps are bolted to the bed plate, worked by reumps from separator to boiler.

is of mild steel, $33 \%$ inches in diameter,

The screw, of bronze, is four bladed; diameter, 48 The armament, which the boat is now awaiting, will fense a Hotchkiss revolving cannon, hand grenades,
fend and small arms.

It was originally contemplated to fit the boat with two bow tubes for ejecting the torpedoes ahead, diwo bow tubes for ejecting the torpedoes ahead, di. There is one furnace, with two doors opening der, 12 inches; of low pressure cylinder, 21 inches. ne : Two air pumps from condenser to hot well, two weighing 1,000 pounds. 
anchors and gear, and dead weight representing armament) of one-third of that displacement.

Her best recorded run over the measured nautical mile was made in $2 \mathrm{~m}$. $35.2 \mathrm{sec}$., or at the rate of $23 \cdot 195$ knots, equal to $26 \cdot 709$ statute miles per hour.
During this run the pressure in the boiler was $164 \cdot 5$ pounds, intermedial 36.5 pounds, vacuum 19 inches (mercury), air pressure in fire room 3.5 inches (water), horse power, estimated, 560 .

During a three hour continuous run at full power she made 59 nautical miles, giving an average of $193 / 4$ knots, equal to 22.646 statute wiles per hour. While this run was in progress, time was taken twice over the measured nautical mile course, no notice being given to engineers or firemen, nor any attempt made to spurt the boat, and she was found, from the mean of the two observations, to be making $19 \cdot 616$ knots. Average number of revolutions for the three

minute. Horse power, estimated, 380

In her contests in speed with other boats she has won a high reputation, trying the issue unhesitatingly with others much superior in size. Her two most nota-
ble races have been. one in June, 1885, with the Mary Powell, and the other in July of the same year as a contestant in the American Yacht Club regatta. In the former race, without being pushed to the utmost, she a run from the foot of West 23d Street to Tarrytown. In the latter race, being entered with the Atalanta, Radha, Cramps, "246," Otowana, and seven others, she made the run from Larchmont to New London in $4 \mathrm{~h} .13 \mathrm{~m}$. 31 sec., beating her chief rival, the Atalanta, by $40 \mathrm{~m} .19$ sec., but not securing the prize, the judges deciding that she had not rounded the buoy at the finish, a fatal technical deficiency, but one of no material

time.

Since her acquisition by the government she has, of course, been entered in no races, but various runs
made over the measured mile under varying conditions of load and steam show that she has suffered no diminution of power. She bids fair to live a long and useful life. In her present solitary condition she and and seamen. Accompanied by sisters, valuable practice in flotilla evolutions would be possible in peace, and in war the naval contingent, that right arm of our coast defense, would be so much the more muscular. First class or sea-going torpedo boats should compose our flotilla of the future, capable of operating in all weathers and with a large radius of action. article is rated, are of chief value in defenee of harbors and of inclosed waters, and will be able to serve, in other than very stormy weather, in operations extending to about two hundred miles from the coast.

Five tons of coal will drive the Stiletto 112 knots at a speed of 18 knots per hour, and 515 knots at a speed of 11 knots per hour. Each ton of coal additional will inknots to the former distance and 100 knots to the latter.

In a rough sea test, to ascertain the strength of the boat and its qualities in heavy weather, remarkably good behavior was manifested. The boat rolled but little when put in the trough of the sea and, steaming head on, spray alone came aboard, no solid water being shipped. The distance run was $41 \cdot 17$ knots and it was made in $2 \mathrm{~h}$. $22 \mathrm{~m}$. 41 sec. giving an avera

knots, equal to 19.93 statute miles per hour

Our illustrations give, Fig. 1, a view on deck looking forward; Fig. 2, the interior of the conning tower; Fig. 3, a view on deck looking aft; Fig. 4, the after part of the quarters for the crew; Fig. 5 , the boat as seen from astern; Fig. 6, the helmsman at his post and the officers'
stateroom; Fig. 7, the engine room; Fig. 8 , the boiler room; Fig. 9, the galley; and Fig. 10, a broadside view of the boat.

The Stiletto, aside from the beauty of her model and the wonderful record achieved, and beyond the admiration evoked by the striking originality of her component parts, to the harmonious working of which her success is due, excites particular interest from the fact that she is the first torpedo boat designed for the use of automobile torpedoes ever owned by the United States.

The government has, up to a recent date, relied mainly on spar torpedoes for use in torpedo warfare. Nearly all our monitors, a few of our tugs, and all of our ships, from the close of the civil war to the beginning of the present era of "the new navy," have been fitted with them, and each ship has been and still continues to be furnished with at least one

provided with means for operating them.

With the exception of these launches, we have owned but few torpedoboats, properly so designated, and of these few but one, prior to the acquisition of the Stiletto, has been distinguished for speed. The of a Frenchman at an early period of the civil war attained a speed, under sixteen oar power, of $2 \frac{1}{2}$ knots. Her torpedo, affixed to the hull of an enewy by a man in a diving suit emerging from the interior of the boat was to explode, after an interval, through the action of clock work contained within it. 'This boat, son utter failure, foundered at sea. The next was the Spuyten Duyvil, built toward the close of the civil war, carrying an under-water spar ahead. Speed low. She is no
longer on the navy list. The Intrepid, built in 1874 longer on the navy list. The Intrepid, built in 1874, was the third, fitted at first with a submerged ispar and
later with towing torpedoes and with ordinary abovewater spars on either beam. Speed between 10 and 11 knots. Proving a failure as a torpedo vessel, she is now being converted to a light draught gunboat. In 1874 was also built the torpedo ram Alarm, carrying a spar torpedo ahead and one on either beam. Speed 11
knots. She is now in ordinary at New York. In 1875 knots. She is now in ordinary at New York. In 1875 the Lightning was built by the Herreshoff Manufac-
turing Company for the Bureau of Ordnance. This boat attained a speed of $20 \frac{1}{3}$ statute miles, equal to $17 \frac{2}{3}$, knote, a record which has never been equaled by any torpedo station, worn out in service.

The high efficiency realized by the Lightning and the
orpedo station, worn out in service. tiletto gives cause for belief that a new and larger teel torpedo boat, now building by the Herreshoff Manufacturing Company, under contract with the overnment, will yield results which will do this enterIt is to be hoped that other boats may follow soon and that, while other nations are building by dozens and by scores, our government may see the wisdow of increasing these valuable adjuncts of the naval force mor rapidly than by occasional units.

\section{Flying Fish.}

At a recent meeting of the Physiological Society, Berlin, Prof. Moebius spoke on the movements of the flying fish through the air. He first described, from personal observation, the way in which the fish shoot out of the water from both bows of the ship, and then propel themselves horizontally for a distance of several
ship's lengths with their pectoral and abdowinal fins stretched out flat, skimming along without moving their fins, always in the direction of the wind, but either with or against the same. When they meet the crest of a wave they raise themselves slightly in the air, falling again to the same extent in the succeeding trough of the sea. Occasionally a slight buzzing of the fins may be observed, similar to that of the movements of
the wings in many insects. At night they frequently the wings in many insects.
fall on the deck of the ship.

As a result of a detailed investigation, the speak had proved that these fish do not fly, since the anatomical arrangements of their fins and muscles are not adapted to this purpose. What really occurs is that adapted to this purpose. What really occurs is that
when frightened by the approach of a ship or any enemy they shoot up out of the water, as do so many other
fish, and are then carried along by the wind, which strikes on the under surface of their outstretched and evenly balanced fins. Notwithstanding the general ac-
ceptance which was accorded to the above investigation, it was urged by many that the buzzing of the fins, the rising over the crest of a wave, and the falling overboard after having landed on the deck of a ship, were evidences that this fish really executes movements which result in flight. In reply to this, the speaker pointed out that the buzzing of the fins takes place when a strong
current of air is directed against the outspread fins of a dead flying fish by means of a bellows, and further that the rising over the crest of a wave or the bulwarks of a ship may be explained by the ascending currents of air which are always produced whenever a strong horizontal wind strikes against any elevated object, such as a wave or part of a ship. Thus, finally,
with the exception of the movements involved in its with the exception of the movements involved in its
oblique sudden exit from the sea, all the motions of a flying fish when in the air are really passive.

Explosive silver and lodine Compounds.

An imperfect argentine fulminate, although one of violently explosive character, is prepared by digesting recently precipitated oxide of silver in ammonia for
welve hours, then pouring off the liquid and cautioustwelve hours, then pouring off the liquid and cautious-
ly drying the black powder in the air, having previousy divided it into small portions. This is a most violent explosive, hut not quite so much so as some crystals hich are obtained from the ammoniacal liquid that deposits, on cooling, small crystals which will scarcely deposits, on cooling, small crystals which will scarcely
bear touching, even while under the liquid. A modifcation of this consists in dissolving chloride of silver in ammonia, adding caustic potash in fragments, and when effervescence ceases decanting the fluid portion and washing and drying the powder. These were are not now considered to be a true fulminate of silver, being simply oxide of silver and ammonia.

The true fulminate is formed by adding alcohol to a warm solution of acid nitrate of silver. We give a formula for its preparation on the principle upon
which sunken rocks aremarked on the mariner's chart, viz., as something to be avoided when experimenting with chemicals in everyday use. Pour one ounce of of silver, and add as ounce of nitric acid. When the hausted. nitrate assumes a white, cloudy appearance, cold water
is added to suspend the ebullition, and the powder is collected on a filter and divided into small portions. This is Brugnatelli's method; but those of Fownes and Liebig differ from it in no important respect. For exmple, the latter dissolves one part of metallic silver in ten parts of nitric acid, and then pours the solution into twenty-three parts of alcohol. This is heated to the boiling point, and is set aside to cool, when the fulthe weight of which, after being washed, equals that f the silver originally employed.

From the foregoing it will be seen how near to the wind photographers may sail without running foul of his wost deadly compound, which only a few years ago was stated to be the most dangerous substance for Which we are indebted to modern chemistry. It is cerphotography, not excepting the iodide of nitrogen, a substance which at one time was recommended as giving a rewarkable degree of sensitiveness when employed in photography. Indeed, in the earlier times, even the fulminates, not only of silver, but of the other metals, were suggested as being likely to possess marvelous sensitive-conferring properties. Friction or percussion are stated as means whereby the explosion of fulminating silver is effected, but such friction and percussion need be only very slight. indeed-a touch of feather and the fall of a drop of water upon the compound have been known to do the mischief.

We have alluded to iodide of nitrogen. We feel it to be a duty to refer to the fatal facility with which thi substance can be formed. A few crystals of iodine it to effect its solution-and that is all. The over pound arising from this simple mixture is the deadly ter-iodide of nitrogen. Such a mixture has been recommended, and is employed by many, for removin pyro stains from the fingers. When used aright, it is quite harmless, the condition of safety being found in there being an excess of the indine. This solution was stated by the late Rev. J. B. Reade, F.R.S., at that form an ant in dissolving old under society, to valuable and interesting to microscopists. A drop is placed upon a microscopic slide, and a bit of gold lea is laid thereon; this dissol ves and forms beautiful tree and shrub like growths of bright gold.

When photographers feel it incumbent on them to use iodide of nitrogen, they ought to take special care not to allow it to be placed aside where it will dry and crystallize, as in this form it cannot bear to be touched. Even the very act of throwing it away may lead to its exploding ere it is projected into the waste. $-B ;$ itish Journal of Photography.

\section{Rounds in 27 seconds.}

Some interesting experiments were made recently and automatic guns. The first Nordenfelt quick-firing Maxim automatic gun of 0.45 caliber, and with this 334 rounds were fired in twenty-seven seconds. A comparative test was then made between ordinary rifle powder and the new Maxim smokeless powder. A cartridge containing 85 grains of black powder and others containing 55 grains of the new powder were fired. The last mentioned cartridges gave a slightly greater velocity, and at the same time produced exwas an automatic six pounder, which has a dropping block like the Sharpe's rifle. It requires only two men to work it, one firing and the other loading. Everything about the gun is fixed save the gun itself, which is placed inside a jacket, which latter is also fixed. There The gun on being fred rearils about $4 \frac{1}{2}$ inches, and then returns to its original position. 'I'he cartridge case is not ejected till the gun has traveled some little distance on its return journey. The act of putting in the new cartridge pushes forward the ejectors and re leases the block, which rises and closes the breech. If great rapidity is required, one man on a saddle with a butt to his shoulder aims and fires, while a man on ach side puts in the cartridges. If only one gunner following manner: Having laid the gun and in the trigger in a firing position by a bit of wood or string, he simply puts in cartridge after cartridge, the gun on each. occasion going off as the cartridge is pushed forward. It can be fired, with two men to load, sixty

\section{Ingenious Mode of Advertising.}

The agents for a certain kind of cough candy distribute circulars on which is stated the following puzzle: "What number can you take, and when you divide it by two, three, four, five or six you will have one over,
but when divided by seven nothing will remain?" The circular goes on to say that if a person cannot solve the puzzle he should buy a box of the candy, when the agent will hand him the right number on a slip of 